\title{
Superparamagnetic iron oxide nanoparticles conjugated with epidermal growth factor (SPION-EGF) for targeting brain tumors
}

This article was published in the following Dove Press journal:

International Journal of Nanomedicine

3 January 2014

Number of times this article has been viewed

\author{
Maxim A Shevtsov 1,2 \\ Boris P Nikolaev ${ }^{3}$ \\ Ludmila Y Yakovleva ${ }^{3}$ \\ Yaroslav Y Marchenko ${ }^{3}$ \\ Anatolii $\vee$ Dobrodumov ${ }^{4}$ \\ Anastasiya L Mikhrina ${ }^{5}$ \\ Marina G Martynova' \\ Olga A Bystrova' \\ Igor V Yakovenko² \\ Alexander M Ischenko ${ }^{3}$ \\ 'Institute of Cytology of the \\ Russian Academy of Sciences (RAS), \\ ${ }^{2} A L$ Polenov Russian Scientific \\ Research Institute of Neurosurgery, \\ ${ }^{3}$ Research Institute of Highly Pure \\ Biopreparations, ${ }^{4}$ Institute of \\ Macromolecular Compounds of the \\ Russian Academy of Sciences (RAS), \\ ${ }^{5} \mathrm{IM}$ Sechenov Institute of Evolutionary \\ Physiology and Biochemistry of the \\ Russian Academy of Sciences (RAS), \\ St Petersburg, Russia
}

Correspondence: Maxim A Shevtsov Institute of Cytology of the Russian Academy of Sciences (RAS), 194064 Tikhoretsky Ave 4, St Petersburg, Russia

Tel +78122977450

Fax +7812297034 I

Email shevtsov-max@mail.ru

\begin{abstract}
Superparamagnetic iron oxide nanoparticles (SPIONs) conjugated with recombinant human epidermal growth factor (SPION-EGF) were studied as a potential agent for magnetic resonance imaging contrast enhancement of malignant brain tumors. Synthesized conjugates were characterized by transmission electron microscopy, dynamic light scattering, and nuclear magnetic resonance relaxometry. The interaction of SPION-EGF conjugates with cells was analyzed in a C6 glioma cell culture. The distribution of the nanoparticles and their accumulation in tumors were assessed by magnetic resonance imaging in an orthotopic model of C6 gliomas. SPION-EGF nanosuspensions had the properties of a negative contrast agent with high coefficients of relaxation efficiency. In vitro studies of SPION-EGF nanoparticles showed high intracellular incorporation and the absence of a toxic influence on C6 cell viability and proliferation. Intravenous administration of SPION-EGF conjugates in animals provided receptor-mediated targeted delivery across the blood-brain barrier and tumor retention of the nanoparticles; this was more efficient than with unconjugated SPIONs. The accumulation of conjugates in the glioma was revealed as hypotensive zones on T2-weighted images with a twofold reduction in T2 relaxation time in comparison to unconjugated SPIONs $(P<0.001)$. SPION-EGF conjugates provide targeted delivery and efficient magnetic resonance contrast enhancement of EGFR-overexpressing C6 gliomas.
\end{abstract}

Keywords: brain tumor, C6 glioma, magnetic nanoparticles, EGFR, epidermal growth factor, MRI contrast agent, SPION

\section{Introduction}

Superparamagnetic iron oxide nanoparticles (SPIONs) with a diameter $<50 \mathrm{~nm}$ represent an important novel class of magnetic resonance imaging (MRI) contrast agents for the medical imaging of brain tumors. ${ }^{1}$ SPIONs cannot only be applied for the diagnosis of tumors and metastases, but also for therapeutic purposes, using hyperthermia generated by an electromagnetic field. ${ }^{2,3}$ Iron oxide nanoparticles in a magnetic field can generate signal contrast levels that are significantly higher than paramagnetic gadolinium chelates, providing an opportunity for the early detection of tumors. Further studies have demonstrated that surface functionalization of SPIONs by various bioligands can increase the specificity of brain tumor targeting. ${ }^{1,4}$ One of the most promising markers for malignant gliomas is the amplification of epidermal growth factor receptor (EGFR) expression with a frequency of about 50\%. 5,6

The EGFR (ErbB1) belongs to the ErbB family of receptor tyrosine kinases, which also includes human epidermal growth factor receptor (HER)-2/ErbB2, HER-3/ErbB3, and HER-4/ErbB4. ${ }^{7}$ Several mutant forms have been described; 
EGFRvIII is the most common. ${ }^{8}$ In comparison to other EGFRs, the mutant form of EGFRvIII is tumor-specific and is not expressed in normal tissues. ${ }^{9}$ Due to the prevalence of wild-type (wt)EGFR and EGFRvIII in malignant gliomas, this makes them attractive targets for antitumor therapies. Currently, numerous therapeutic approaches that target EGFR have been proposed, including monoclonal antibodies, ${ }^{10-12}$ vaccines, ${ }^{13,14}$ ribonucleic acid-based agents, ${ }^{15}$ and tyrosine kinase inhibitors. ${ }^{16}$ Previously, Hadjipanayis et $\mathrm{al}^{2}$ reported the possibility of glioma targeting with iron oxide nanoparticles conjugated to a purified antibody that selectively binds to EGFRvIII. The authors demonstrated the accumulation of nanoparticles (EGFRvIIIAb-IONP) in the tumor after convection-enhanced delivery with a subsequent inhibition of glioblastoma growth. However, this approach has limited clinical relevance due to the local application of nanoparticles. Furthermore, the specific antibodies were only aimed towards a subpopulation of EGFRvIII-positive cells, sparing subsets of tumor cells with wtEGFR or other mutant receptor forms. Thus, the application of epidermal growth factor (EGF), which is the natural ligand of EGFR, could help cover all of the subsets of tumor cells expressing wtEGFR, as well as its mutant forms. Several studies have demonstrated the feasibility of tumor targeting in various models by the conjugation of EGF to nanoparticles. ${ }^{17-19}$ Thus, in a recent publication, Sandoval et $\mathrm{al}^{20}$ demonstrated the therapeutic efficacy of stearoyl gemcitabine nanoparticles conjugated to EGF in a breast adenocarcinoma mouse model.

In our previous studies, ${ }^{21}$ we developed iron oxide nanoparticles conjugated to EGF. These modified nanoparticles were shown to have high diagnostic potency in intravenous (IV) delivery in models of subcutaneous melanoma (clone-M3) and MN-22a hepatoma cells. It has been shown in experimental models that the IV administration of conjugates leads to an enhancement in magnetic resonance (MR) imaging contrast in areas of accumulated cancer cells. ${ }^{21}$ In the present study, we demonstrate the possibility of targeting EGFR-overexpressing brain tumors by magnetic nanoparticles conjugated to EGF in a C6 glioma model.

\section{Materials and methods}

\section{Synthesis and characterization of the SPION-EGF conjugates}

\section{Synthesis of SPION}

SPIONs were prepared from iron salt solutions by coprecipitation in alkaline media at $80^{\circ} \mathrm{C}$, according to Massart. ${ }^{22}$ $\mathrm{FeSO}_{4}$ and $\mathrm{FeCl}_{3}$ at an $\mathrm{Fe}^{+} / \mathrm{Fe}^{+}$ratio of $1: 2$ were dissolved in water with the addition of $\mathrm{CsCl}$. Magnetite precipitation was induced by titration with an $\mathrm{NH}_{4} \mathrm{OH}$ solution in an inert atmosphere under vigorous stirring in a $100 \mathrm{~mL}$ reactor. Magnetite was formed as a black precipitate by the following reaction:

$$
2 \mathrm{Fe}(+3)+\mathrm{Fe}(+2)+8 \mathrm{OH}^{-} \rightarrow \mathrm{Fe}_{3} \mathrm{O}_{4}+4 \mathrm{H}_{2} \mathrm{O} .
$$

The precipitate was collected by a permanent magnet. The magnetite suspension in water was treated by ultrasound at $22 \mathrm{KHz}$ for 15 minutes. To prevent sedimentation, low molecular weight dextran (molecular weight: 10 kD; SigmaAldrich Corporation, St Louis, MO, USA) was added to the dispersion during the process of ultrasound application. The prepared stock solution of nanoparticles was washed and separated into fractions by centrifugation and microfiltration using $0.2 \mu \mathrm{m}$ pore membranes (EMD Millipore, Billerica, MA, USA). The fine fraction of SPIONs was characterized and stored in water at $4^{\circ} \mathrm{C}$ prior to the preparation of the conjugates. The Fe content in the suspension was controlled by the ultraviolet absorption of the thiocyanate-Fe $(+3)$ complex at $\lambda=480 \mathrm{~nm}$.

\section{SPION-EGF conjugate synthesis}

Recombinant human EGF was obtained from Protein Contour Company Ltd (St Petersburg, Russia). The dextran coating on the magnetic nanoparticles was cross-linked with epichlorohydrin and aminated. Magnetic nanoparticles were suspended in a phosphate buffered solution of EGF $(60 \mu \mathrm{g} / \mathrm{mL})$ (Figure 1). The conjugation reaction was carried out at $20^{\circ} \mathrm{C}$ with shaking for 1 hour. Soluble carbodiimide dextran was activated by water and coupled to the carboxyl groups of EGF, producing a magnetic conjugate.

The specific immune activity of the synthesized SPIONEGF conjugates was estimated by a magnetic relaxation switch assay. ${ }^{23,24}$ Briefly, the prepared SPION-EGF nanosuspensions were mixed with anti-EGF rabbit polyclonal antibodies (1:250) (Protein Contour Company Ltd) and transferred to the magnetic field of a 7.1 T Bruker spectrometer (CXP-300; Bruker BioSpin, Billerica, MA, USA). The magnetic relaxation times ( $\mathrm{T} 1$ and $\mathrm{T} 2$ ) of the water proton resonance were measured with help of inversion recovery and Carr-Purcell-Meiboom-Gill impulse sequences at different terms of exposure in the magnetic field. The water proton relaxation behavior was compared with SPION samples that were not treated by anti-EGF antibodies. Additionally, we analyzed the relaxation times of the samples of SPIONs mixed with anti-EGF antibodies to assess the nonspecific binding of the antibodies. 


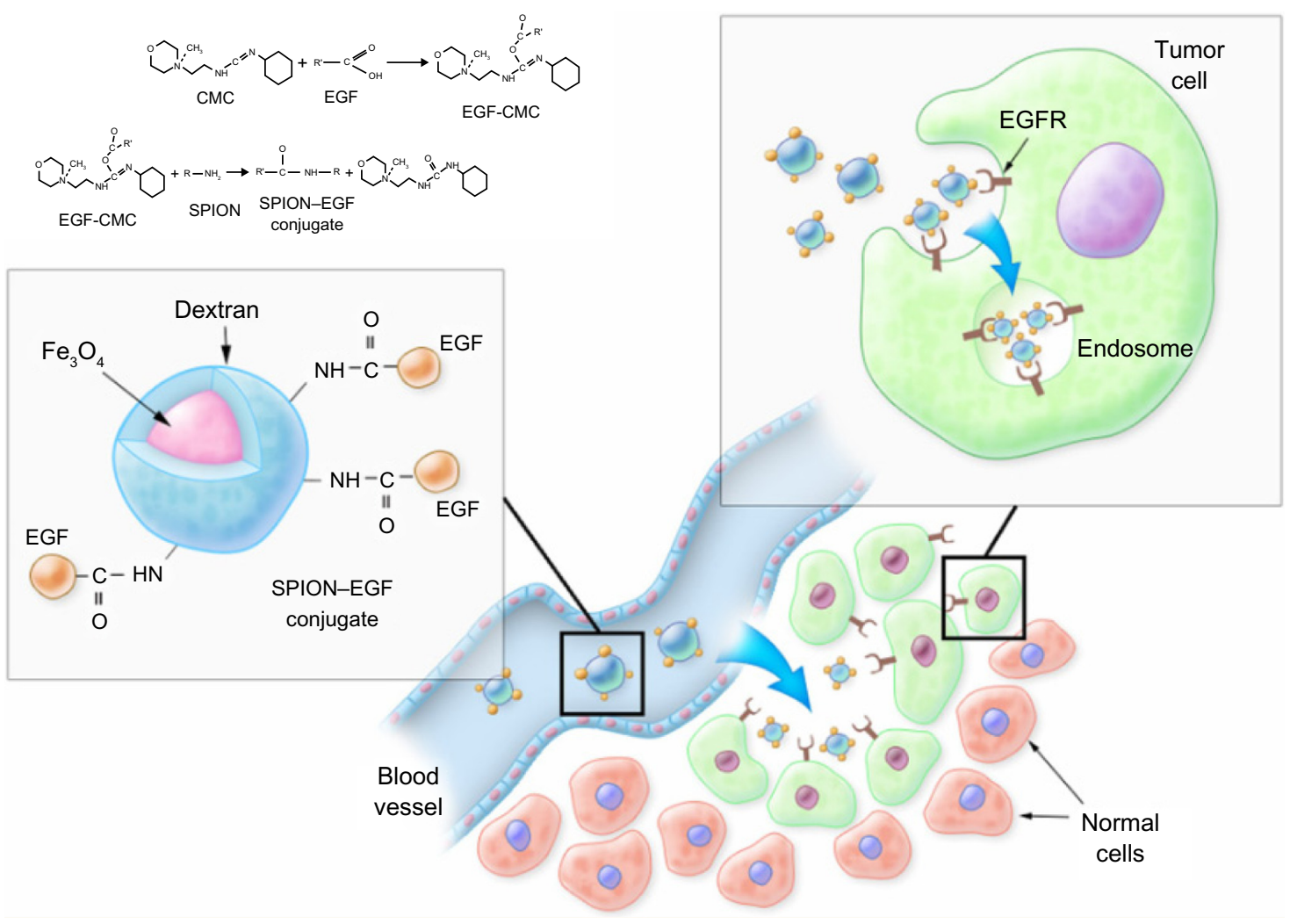

Figure I Scheme of the synthesis and function of SPION-EGF conjugates in tumors.

Notes: Synthesis of the magnetic nanoparticle conjugate is presented in the top left. Briefly, dextran-coated nanoparticles were crosslinked with epichlohydrin and were aminated. Activated by CMC, dextran was coupled to carboxyl groups of EGF protein producing SPION-EGF conjugate. Being intravenously injected, nanoparticles (due to the disrupted blood-brain barrier) can accumulate in the tumor site. Receptor-mediated endocytosis of the EGF-functionalized nanoparticles by the EGFR-overexpressing cells (top right) can provide the retention of nanoparticles in the tumor.

Abbreviations: CMC, water-soluble carbodiimide; EGFR, epidermal growth factor receptor; SPION, superparamagnetic iron oxide nanoparticle; SPION-EGF, superparamagnetic iron oxide nanoparticles conjugated with epidermal growth factor.

The content of Fe in the magnetic EGF conjugate samples was analyzed by spectrophotometry of the thiocyanate$\mathrm{Fe}(+3)$ complex, prepared by $\mathrm{HNO}_{3}$ dissolution. The EGF content in conjugate samples was measured using a human EGF enzyme-linked immunosorbent assay (ELISA) kit (Protein Contour Company Ltd) following the manufacturer's protocol.

\section{Physicochemical study of SPION-EGF conjugates}

The particle size and size distribution of SPION and its conjugates were studied by transmission electron microscopy (TEM) using a JEOL-2000 microscope (JEOL, Tokyo, Japan) and dynamic light scattering (DLS) using a Malvern instrument. The hydrodynamic size and electrophoretic properties were measured on Zetasizer Nano (Malvern Instruments, Malvern, UK). Nuclear MR (NMR) spectra and magnetic relaxation times (ie, T1, T2, and T2*), were measured using CXP-300, a NMR-spectrometer with a magnetic field of $7.1 \mathrm{~T}$. The proton MR of water protons was observed at $300 \mathrm{MHz}$. The magnetic nanoparticle suspensions were sampled in standard $5 \mathrm{~mm}$ tubes. The NMR spectra were registered by Fourier transform of one-pulse induction decay. T2* was calculated as $(\pi \Delta v)-1$ where $\Delta v$ is the width of line in $\mathrm{Hz}$ measured at half height. To estimate the magnetic relaxation times, the inversion recovery and Carr-Purcell-Meiboom-Gill impulse sequences were applied. Proton relaxation times were studied as a function of the magnetic EGF conjugate concentration in a buffered solution. The coefficients of relaxation efficiency (ie, $R_{l}, R_{2}$, and $R_{2}^{*}$ [relaxivity]), were determined from the slopes of the concentration plots.

\section{Preparation and MR analysis of the agar phantom samples}

The relaxation efficacy of SPION or SPION-EGF conjugates was evaluated using gel phantoms prepared from agar (BD, Franklin Lakes, NJ, USA). Briefly, 5\% agar gel was melted and mixed with SPION or SPION-EGF nanoparticles. The glass tube (11 $\mathrm{mm}$ in diameter) was filled with melted agar-containing magnetic nanoparticles at various $\mathrm{Fe}^{+}$ 
concentrations $(0.1 \mathrm{mM} / \mathrm{L}, 0.2 \mathrm{mM} / \mathrm{L}, 0.3 \mathrm{mM} / \mathrm{L}$, and 0.4 $\mathrm{Fe} 3^{+} \mathrm{mM} / \mathrm{L}$ ). The tubes were cooled at $4^{\circ} \mathrm{C}$ for 10 minutes and placed into the MR scanner for study (Bruker). MR measurements were performed on T2-weighted scans (Turbo RARE-T2 regimen). Additionally, we performed gradientecho fast imaging (GEFI), multiscan-multiecho (MSME), and RARE-T1 scanning regimes.

\section{Assessment of SPION-EGF conjugate interactions with $\mathrm{C} 6$ glioma cells C6 glioma cells}

The rat glioma line (C6) was obtained from a panel of tumor cell lines in a collection from the Institute of Cytology, Russian Academy of Sciences (St Petersburg, Russia). The cells were cultured in Dulbecco's Modified Eagle's Medium, supplemented with 10\% fetal bovine serum, $2 \mathrm{mM}$ of L-glutamine, 100 units/mL of penicillin $\mathrm{G}$, and $100 \mu \mathrm{g} / \mathrm{mL}$ of streptomycin (Gibco ${ }^{\circledR}$; Life Technologies, Carlsbad, CA, USA). In all experiments, cells were maintained in $100 \mathrm{~mm}$ culture dishes (Nunc; Thermo Fisher Scientific, Waltham, $\mathrm{MA}, \mathrm{USA}$ ) at $37^{\circ} \mathrm{C}$ in a humidified $5 \% \mathrm{CO}_{2} / 95 \%$ air atmosphere. Before the experiments, cells were harvested in the log phase of growth, and their viability was determined by $0.4 \%$ Trypan blue exclusion.

\section{Cell viability and proliferation}

Cells were incubated with phosphate buffered saline (PBS; control), SPION (150 $\mu \mathrm{g} / \mathrm{mL})$, or SPION-EGF (150 $\mu \mathrm{g} / \mathrm{mL})$ conjugates for 1 hour, 3 hours, 12 hours, and 24 hours in a $\mathrm{CO}_{2}$ incubator. Following incubation, cells were washed and viability was assessed by $0.4 \%$ Trypan blue exclusion. Additionally, the 3-(4,5-dimethylthiazol-2-yl)2,5 diphenyl tetrazolium bromide (MTT) assay was used to test the cytotoxicity of the magnetic nanoparticles and cell proliferation. We applied the Vybrant ${ }^{\circledR}$ MTT Cell Proliferation assay kit according to the manufacturer's protocol (Life Technologies).

\section{Confocal microscopy}

C6 cells were allowed to settle on poly-L-lysine-coated glass slides. Cells were incubated with SPION $(150 \mu \mathrm{g} / \mathrm{mL})$ or SPION-EGF $(150 \mu \mathrm{g} / \mathrm{mL})$ conjugates for 1 hour, 3 hours, 12 hours, and 24 hours at $37^{\circ} \mathrm{C}$. After incubation with nanoparticles, cells were extensively washed, and they were then fixed with $4 \%$ paraformaldehyde in PBS. The nuclei were stained with 4',6-diamidino-2-phenylindole (DAPI). Glasses were mounted in Dako fluorescent mounting medium (Dako North America Inc, Carpinteria, CA, USA). For the confir- mation of EGFR-mediated endocytosis, we applied blocking anti-EGFR antibodies. Briefly, C6 cells were incubated with an anti-EGFR antibody (1:100 dilution). Following incubation with the antibody, cells were further incubated for 24 hours with SPION or SPION-EGF conjugates, and the incorporation of nanoparticles was analyzed by confocal microscopy.

For the analysis of magnetic nanoparticle incorporation, reflected laser scanning was applied. Fluorescent images were captured with a Leica TCS SP5 confocal system, equipped with lasers exciting at $488 \mathrm{~nm}(\mathrm{Ar} / \mathrm{Kr})$ and $405 \mathrm{~nm}$ (diode laser) on a Leica DM IRBE microscope (Leica Microsystems, Wetzlar, Germany). To avoid possible cross-talk of the various fluorochromes, the width of the detection channels and filter settings were carefully controlled, and furthermore, images were acquired using the sequential image recording method. For the evaluation of colocalization, single Z-planes were analyzed with Leica confocal software (LCSLite; Leica Microsystems) and ImageJ 1.37 (Wright Cell Imaging Facility, Toronto, ON, Canada). Image presentation, size, and contrast were adjusted with Photoshop 7.0 software (Adobe Systems Incorporated, San Jose, CA, USA).

\section{Transmission electron microscopy} and immunogold labeling

For TEM following incubation with SPION or SPION-EGF conjugates for 24 hours, cells were detached with trypsin/ ethylenediaminetetraacetic acid from the culture plate, fixed in $2.5 \%$ glutaraldehyde in $0.1 \mathrm{M}$ of cacodylate buffer, $\mathrm{pH} 7.4$, for 1 hour at $4^{\circ} \mathrm{C}$, and they were postfixed in $1 \%$ aqueous $\mathrm{OsO}_{4}$ for 1 hour, dehydrated, and embedded in Epon and Araldite; the cells were then sectioned with a diamond knife on an LKB ultratome (Leica Microsystems). Ultrathin sections were collected on fine mesh copper or nickel grids and stained with uranyl acetate and lead citrate for examination with a Zeiss Libra 120 electron microscope (Carl Zeiss Meditec AG, Jena, Germany), which was operated at $80 \mathrm{kV}$.

For immunocytochemical examination, ultrathin sections mounted on nickel grids were first treated with hydrogen peroxide for 20 minutes to loosen the resin. Three washes in PBS for 2 minutes each were followed by incubation with antibodies. For the detection of early endosomes, a rabbit anti-early endosome antigen 1 (EEA-1) polyclonal antibody was applied (Abcam plc, Cambridge, UK) diluted 1:100 in $0.05 \mathrm{M}$ of Tris- $\mathrm{HCl}$ buffer, $\mathrm{pH} 7.4$, containing $1 \%$ bovine serum albumin (BSA) and $0.1 \%$ cold water fish gelatin. For the detection of EGFR-positive endosomes, a rabbit antiEGFR polyclonal antibody was applied (Protein Contour 
Company Ltd), diluted 1:100 in 0.05 M of Tris- $\mathrm{HCl}$ buffer, $\mathrm{pH} 7.4$, containing $1 \%$ BSA and $0.1 \%$ cold water fish gelatin. Incubation with primary antibodies was performed overnight at $4{ }^{\circ} \mathrm{C}$ in a humid chamber. Gold-conjugated $(10 \mathrm{~nm})$ goat anti-rabbit immunoglobulin (Ig)G (Sigma-Aldrich) (diluted 1:10) was used as the secondary antibody, and sections were incubated for 1 hour at room temperature. Finally, the sections were counterstained, as previously described. For the control, the primary antibody was omitted or replaced with an irrelevant antibody.

\section{Magnetic resonance study}

C6 glioma cells $\left(1 \times 10^{6}\right)$ were seeded in triplicate in $30 \mathrm{~mm}$ flat-bottomed plates and incubated overnight at $37^{\circ} \mathrm{C}$ with SPION $(150 \mu \mathrm{g} / \mathrm{mL})$ or SPION-EGF $(150 \mu \mathrm{g} / \mathrm{mL})$ conjugates for 24 hours. Following incubation, cells were washed with PBS, collected after scraping, and placed in $10 \mathrm{~mL}$ tubes in $1 \%$ agarose solution. Cells in agarose without incubation with nanoparticles were used as the control. Additionally, in one sample, prior to incubation of the C6 cells with conjugates, we incubated cells with blocking anti-EGFR antibodies (dilution 1:100) for 4 hours. MR measurements were performed on T2-weighted scans (repetition time [TR]/echo time [TE]: 4,200/36 ms; flip angle: $180^{\circ}$; slice thickness: $1.0 \mathrm{~mm}$; interslice distance: $1.2 \mathrm{~mm}$; field of vision [FoV]: $1.2 \times 1.2 \mathrm{~cm}$; matrix: $128 \times 128)$. Additionally, we performed gradient-echo sequence (GEFI ORTO), MSME, and RARE-T1 scanning regimes.

\section{Analysis of $\mathrm{C} 6$ glioma targeting by SPION-EGF conjugates}

\section{Animals}

Male Wistar rats weighing 280-320 g were purchased from the "Rappolovo" animal nursery (Russian Academy of Medical Sciences, St Petersburg, Russia). All animal experiments were approved by the local government and were conducted in accordance with Institute of Cytology of the Russian Academy of Sciences guidelines on the welfare of animals.

\section{Orthotopic model of C6 glioma}

Animals were anesthetized before they were mounted in a stereotactic frame (David Kopf Instruments, Tujunga, CA, USA) with $10 \mathrm{mg}$ of Zoletyl-100 (tiletamine hydrochloride and zolazepam; Virbac S.A., Carros, France) and $0.2 \mathrm{~mL}$ of 2\% Rometar (xylazine hydrochloride; Bioveta, Ivanovice na Hané, Czech Republic) intraperitoneally. Rat C6 glioma $\left(1 \times 10^{6} / \mathrm{mL}\right)$ cells in $10 \mu \mathrm{L}$ of PBS were injected $3 \mathrm{~mm}$ below the cortical surface using a Hamilton microsyringe (Hamilton
Company, Reno, NV, USA). The stereotactic coordinates corresponded to the nucleus caudatus dexter.

\section{MRI experiments}

To assess the accumulation of magnetic nanoparticles in gliomas, animals were randomly divided into five groups (three animals in each group) on the 20th day after C6 cell administration: 1) IV injection of the PBS (control group); 2) and 3) IV injection of the SPION (300 $\mu \mathrm{L}, 0.3 \mathrm{mg} / \mathrm{kg})$ for 24 hours and 48 hours, respectively; as well as 4) and 5) IV injection of SPION-EGF conjugates $(300 \mu \mathrm{L}, 0.3 \mathrm{mg} /$ $\mathrm{kg}$ ) for 24 hours and 48 hours, respectively. Assessment was performed using a high-field 7.1 T MRI scanner (Bruker BioSpin) with a custom rat coil. High-resolution anatomical T2-weighted scans (TR/TE: 4,200/36 ms; flip angle $180^{\circ}$; slice thickness: $1.0 \mathrm{~mm}$, interslice distance: $1.2 \mathrm{~mm}$; FoV: $3.0 \times 3.0 \mathrm{~cm}$; matrix: $256 \times 256$; in total, 20 slices) were performed in the coronal plane. Additionally, we performed T1-weighted scans (TR/TE: 1,500/7.5 ms; flip angle: 180 ; slice thickness: $1.0 \mathrm{~mm}$; FoV: $3.0 \times 3.0 \mathrm{~cm}$; matrix: $256 \times 256)$ and FLASH (fast low angle shot) scans (TR/TE: 350/5.4 ms; flip angle: $40^{\circ}$; slice thickness: $1.0 \mathrm{~mm}$; FoV: $3.0 \times 3.0 \mathrm{~cm}$; matrix $256 \times 256$ ) in the coronal plane. For an estimation of the accumulation of nanoparticles in the tumor, we utilized MSME MR sequences. The obtained images were analyzed using Analyze software (AnalyzeDirect, Inc, Stilwell, KS, USA). The MSME images were used to generate T2 maps over the tumor region. For a calculation of the tumor contrast enhancement on the T2 maps, we applied the software package Paravision 3.1 (Bruker Corporation, Billerica, MA, USA). On the MSME image for calculation of the T2 values, the region of interest was generated over the tumor area and over the hypotense zone. As a control, the region of interest was generated over the normal brain area (Figure S1). We calculated the histogram, mean, and standard deviation of the T2 values of the tumor.

\section{Histological analysis}

Tumors from rats were fixed overnight in $10 \%$ formalin. The next morning, tissues were embedded in Tissue-Tek ${ }^{\circledR}$ (Sakura Finetek Europe BV, AJ Alphen aan den Rijn, The Netherlands) and stored at $-80^{\circ} \mathrm{C}$. Sections $(5-7 \mu \mathrm{m}$ thick) prepared from these blocks were mounted on Superfrost ${ }^{\mathrm{TM}}$ Plus slides (Thermo Fischer Scientific) and used for the detection of magnetic conjugates through confocal microscopy. Sections were additionally stained with DAPI. Fluorescence images were obtained using a Leica TCS SP5 confocal system (Leica Microsystems). SPION or SPION-EGF conjugates were 
detected by reflecting laser scanning with laser excitation at $488 \mathrm{~nm}(\mathrm{Ar} / \mathrm{Kr})$. Nuclei were detected using a diode laser (405 nm).

Additionally, brain tumor sections were assessed for EGFR expression in three animals. Sections were stained with rabbit anti-EGFR polyclonal antibodies (Protein Contour Company Ltd) diluted to 1:100. Goat anti-rabbit Alexa Fluor ${ }^{\circledR} 555$ antibodies (Life Technologies) were used as secondary antibodies (diluted to 1:500). Nuclei were stained with DAPI. Immunofluorescence images were captured with a Leica TCS SP5 confocal system (Leica Microsystems).

\section{Statistical analysis}

One- or two-tailed Student's $t$-tests were used to evaluate the differences between the control and experimental groups. All data were run using Statistica Version 9.2 for Windows (StatSoft, Inc, Tulsa, OK, USA). $P$-values of $<0.05$ were considered statistically significant for all tests.

\section{Results}

\section{Physical analysis of EGF-SPION in vitro}

The first stage of the study on synthesized EGF conjugates was performed using physical methods in vitro. The prepared formulations of EGF attached to iron oxide nanoparticles appeared to have the typical characteristics of SPIONs, which are known for their different magnetic nanodispersions of various compositions. According to the ELISA assay, the EGF content in the samples was $4 \mathrm{ng} / \mathrm{mL}$. The TEM images of the EGF conjugate suspensions demonstrate the nanodisperse structure of the EGF formulation (Figure 2A). According to our DLS measurements, the conjugate solutions had a colloidal structure consisting of iron oxide nanoparticles coated by dextran coupled to the EGF protein (Figure 2B). The measured hydrodynamic radius of the iron oxide precursor was $33.7 \mathrm{~nm}$ (Table 1). EGF coupling to the magnetite core increased the mean size of the conjugate to the value of $47.6 \mathrm{~nm}$. As classical nanosols, the prepared samples of conjugates had a broad size distribution with an average deviation of about $21.9 \mathrm{~nm}$. In some cases, the dispersion had a fraction of large particles $(>200 \mathrm{~nm})$, which were separated through repeated centrifugation and magnetic separation in a low magnetic field $(0.02 \mathrm{~T})$.

The resulting suspension suitable for MRI study in the rat model appeared as a black solution stable for 48 hours at $4^{\circ} \mathrm{C}, 20^{\circ} \mathrm{C}$, and $37^{\circ} \mathrm{C}$. The TEM results are in accordance with the DLS study. The dense core of the particles had sizes in the range of 5-10 $\mathrm{nm}$. The EGF conjugate had the
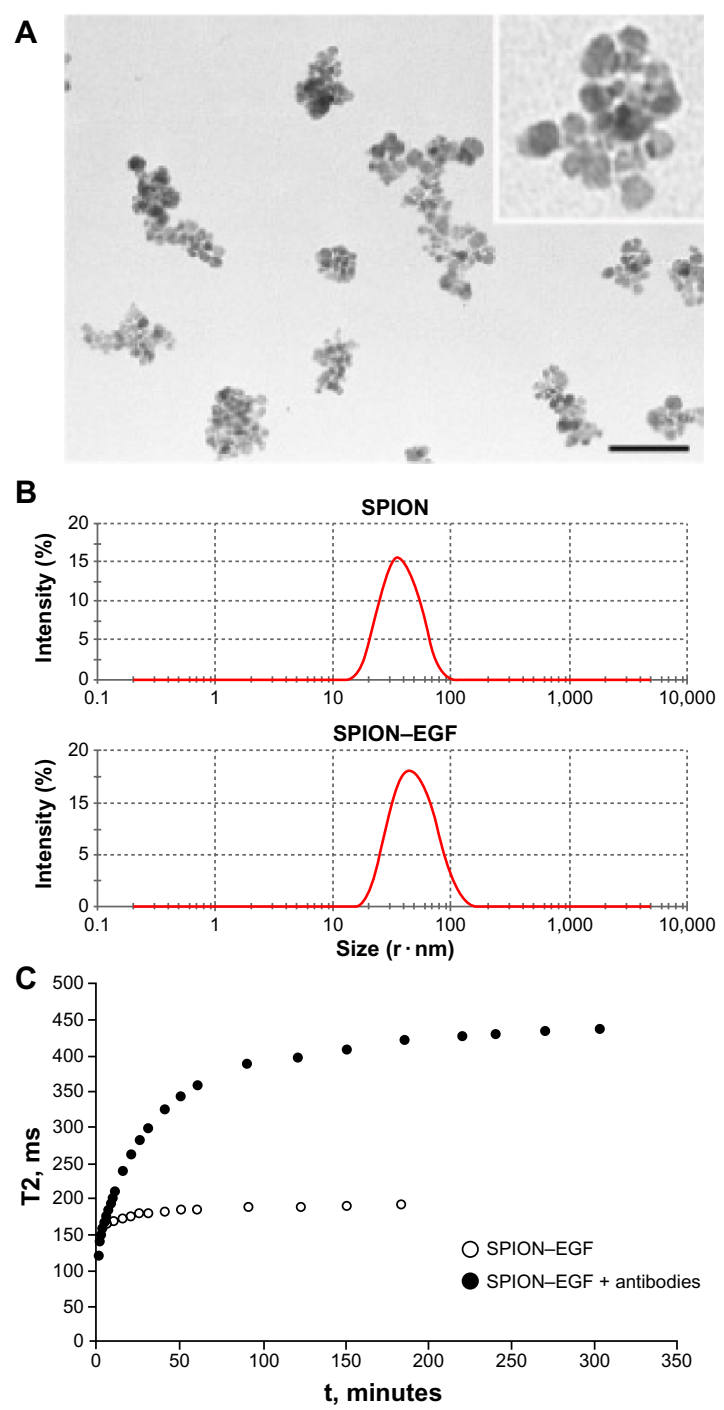

Figure 2 Size and magnetic relaxation assay of the SPION-EGF conjugates in vitro. Notes: (A) Transmission electron microscopy of the SPION-EGF nanoparticles in aqueous dispersion. Scale bar: $100 \mu \mathrm{m}$. (B) Hydrodynamic size $(\mathrm{nm})$ of the SPION or SPION-EGF conjugates in a dilute aqueous dispersion detected by dynamic light scattering using a Zetasizer Nano (Malvern Instruments, Malvern, UK). (C) Magnetic relaxation switch assay on SPION-EGF conjugates. Time evolution of spin-spin relaxation time (T2) of water protons dependent upon the interaction of an EGF conjugate ( $\left.\mathrm{Fe}^{+} 0.02 \mathrm{mM} / \mathrm{L}\right)$ with anti-EGF antibodies $(0.54 \mu \mathrm{g} / \mathrm{L})$ in a uniform magnetic field $(7.1 \mathrm{~T})$ at $20^{\circ} \mathrm{C}$. The magnitude of the change in $\mathrm{T} 2$ relaxation time is significantly higher for the sample of SPION-EGF conjugates that interact with antibodies than in the control set without an antibody.

Abbreviations: SPION, superparamagnetic iron oxide nanoparticles; SPION-EGF, superparamagnetic iron oxide nanoparticles conjugated with epidermal growth factor.

Table I Mean hydrodynamic size of magnetic nanoparticles with and without EGF

\begin{tabular}{lll}
\hline Sample & $\begin{array}{l}\text { Mean hydrodynamic } \\
\text { radius, } \mathbf{n m}\end{array}$ & $\begin{array}{l}\text { Root mean } \\
\text { square deviation }\end{array}$ \\
\hline SPION & 33.7 & 0.13 \\
SPION-EGF & 47.6 & 0.13 \\
\hline
\end{tabular}

Note: The hydrodynamic size $(\mathrm{r}, \mathrm{nm})$ was assessed on Zetasizer Nano (Malvern Instruments, Malvern, UK).

Abbreviations: EGF, epidermal growth factor; SPION, superparamagnetic ion oxide nanoparticle; SPION-EGF, superparamagnetic iron oxide nanoparticles conjugated with epidermal growth factor. 
tendency to aggregate into grape-like structures, similar to other composites (Figure 2A). Each particle was composed of an iron oxide core coated by a dextran shell. Surface-coupled EGF molecules were not visible, but their presence in the shell led to an increase in nanoparticle size.

The conjugation of EGF to aminated SPION did not affect the epitopes responsible for immune recognition to its antibody. In the presence of small amounts of antibody $(0.54 \mu \mathrm{g} / \mathrm{L})$, magnetic relaxometry analysis of SPION-EGF conjugates detected susceptible changes in spin-spin proton relaxation (Figure 2C). The determination of the specific ability of SPION-EGF conjugates was performed by temporal measurements of $\mathrm{T} 2$ relaxation times in a water suspension of the conjugate. This approach was suggested by Tassa et $\mathrm{al}^{23}$ for biosensing antigens, as they observed sensitivity comparable to immune enzyme analysis, independently of the colloid state of the analyte. The sample was inserted in the magnetic field of the NMR spectrometer for different periods of time.
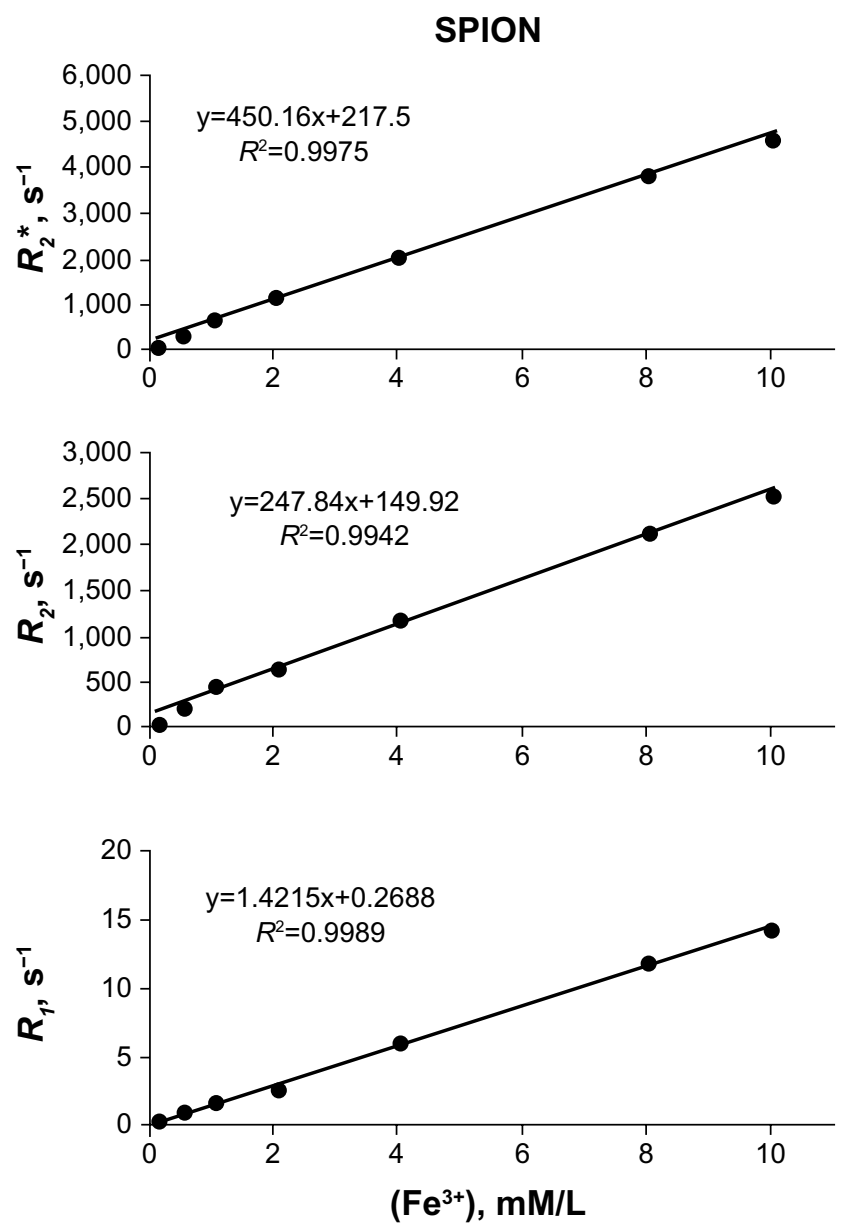

With the addition of the polyclonal human EGF antibody, the T2 transverse time of relaxation increased from $0.17 \mathrm{sec}-$ onds to 0.42 seconds after 6 hours in a homogenous 7.1 $\mathrm{T}$ magnetic field. This increase in $\mathrm{T} 2$ relaxation time was caused by a chain of events leading to the aggregation of conjugate nanoparticles. The initial antigen-antibody formation is the starting point, which is further accompanied by strong magnetic dipole-dipole interactions with the formation of fractal clusters in the strong magnetic field of the NMR spectrometer. The formed clusters influence the proton relaxation of water in the vicinity of SPION aggregates to a great extent, leading to the detection of the immune activity of the EGF complex. The results of the magnetic assay indicate that synthesized SPION-EGF conjugates retained the specific activity of native unconjugated EGF.

The prepared EGF conjugate solutions exhibited the properties of magnetic nanosols from the SPION, as shown by the NMR data (Figure 3). The magnetic relaxation study of EGF
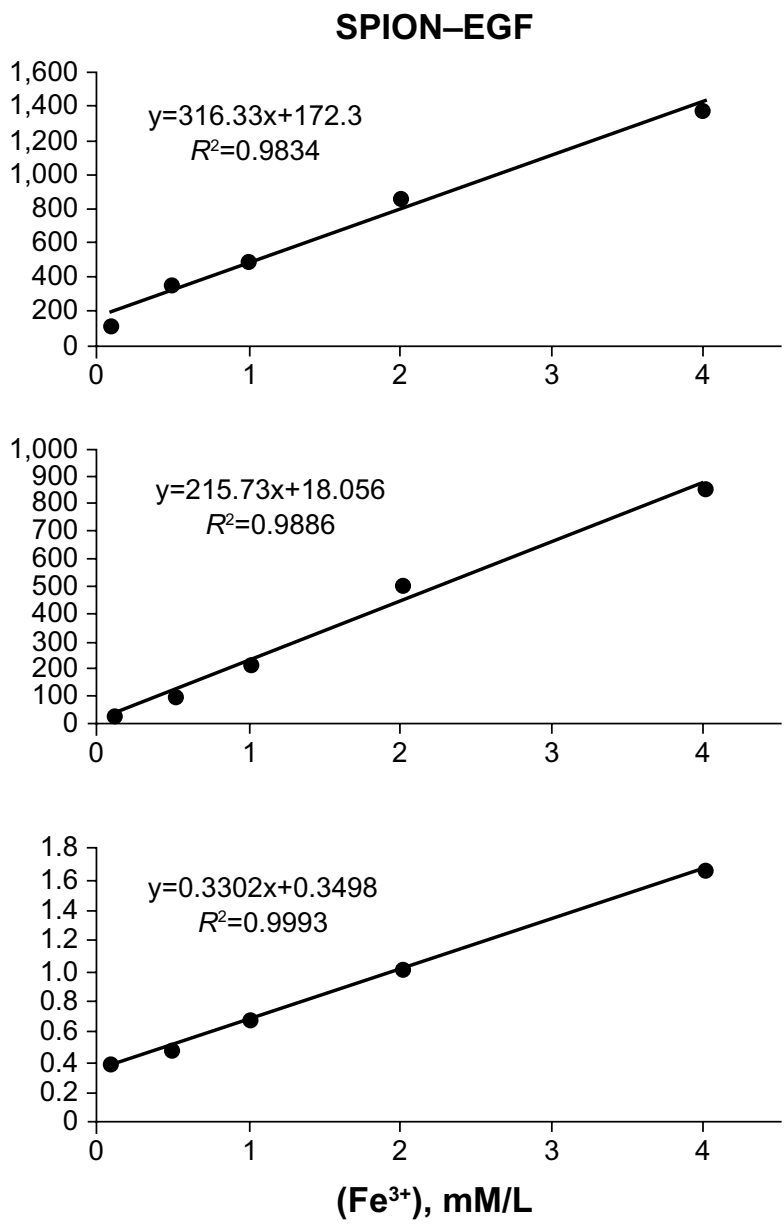

Figure 3 Magnetic relaxation rates $\left(R_{2}^{*}, R_{2}\right.$, and $\left.R_{1}\right)$ of water protons in a nanoparticle dispersion as a function of the Fe $3^{+}$concentration at $20^{\circ} \mathrm{C}$.

Notes: The inverse magnetic relaxation times $\left(R_{1}\right.$ and $\left.R_{2}\right)$ were calculated from a linear fit of logarithmic echo amplitude versus spin echo time. The values of the magnetic relaxation time observed for water protons in the presence of SPION-EGF conjugates are lower in comparison to non-modified SPIONs due to rapid relaxation of spins in an inhomogenous magnetic field induced by the magnetic nuclei in conjugate.

Abbreviations: SPION, superparamagnetic iron oxide nanoparticle; SPION-EGF, superparamagnetic iron oxide nanoparticles conjugated with epidermal growth factor. 
conjugates suggests that there is a strong influence of MR relaxation on water protons, as noted from the presence of iron oxide conjugates in the dispersion. The magnetic relaxation behavior exhibited dose-dependent effects. The decrease in magnetic relaxation times ( $\mathrm{T} 1, \mathrm{~T} 2$, and $\mathrm{T} 2 *$ ) was linearly dependent on the iron content in the suspension measured by the UV absorbance of the thiosulfate coordination complex. Linear fitness was universal for dispersions of variable nature. The viscosity, ionic strength, and cosolvents did not change the linear law of dependence. The observed linear dependence of T2 on the iron concentration can be used as the basis for the estimation of SPION accumulation in tissues by MRI. The inequality of T2 and T1, and very short T2 values, serve as the main indicators of the substantial activity of magnetic iron oxide centers in SPION. The observed effects regarding the strong reduction in proton magnetic relaxation times resembled the activity of superparamagnetic materials in the nanodispersed monodomain state. The relaxation efficiency values were calculated as derivative coefficients of linear concentration dependence plots. The magnetic relaxation rate of SPION-EGF conjugates was correlated with the contrast activity in the dispersion-impregnated phantom gel model. The experimental results on magnetic relaxometry were confirmed by MRI of the phantom samples of the EGF conjugate (Figure 4). The phantom images of agar demonstrated an MR intensity that was in inverse proportion to the SPION concentration in the gel. The greatest contrast changes were recorded in the T2-weighted scanning regime. The intensity of the MR images of EGF conjugates matched well with the phantom samples prepared from suspensions of unconjugated SPIONs. The MR intensity of the impregnated spots in agar was determined only by the total iron concentration. T1-weighted scanning provided evidence of contrast growth, but at a lower rate than the T2-weighted regime.

\section{Accumulation of the SPION-EGF conjugates in $\mathrm{C} 6$ cells}

We investigated the toxic effects of SPION and SPION-EGF on C6 cells, as well as on their proliferation, by the exclusion of Trypan blue and the MTT assay, which were measured in terms of relative viability. We did not observe any influence of the modified and unmodified nanoparticles on the viability of cells at a diagnostic concentration $(150 \mu \mathrm{g} / \mathrm{mL})$. The viability, according to the Trypan blue exclusion assay, did not differ at all time points of incubation (1 hour, 3 hours, 12 hours, and 24 hours) with SPION or SPION-EGF nanoparticles, and this was not different from the control cells (thus, not exceeding 4\%). The standard MTT assay did not reveal any

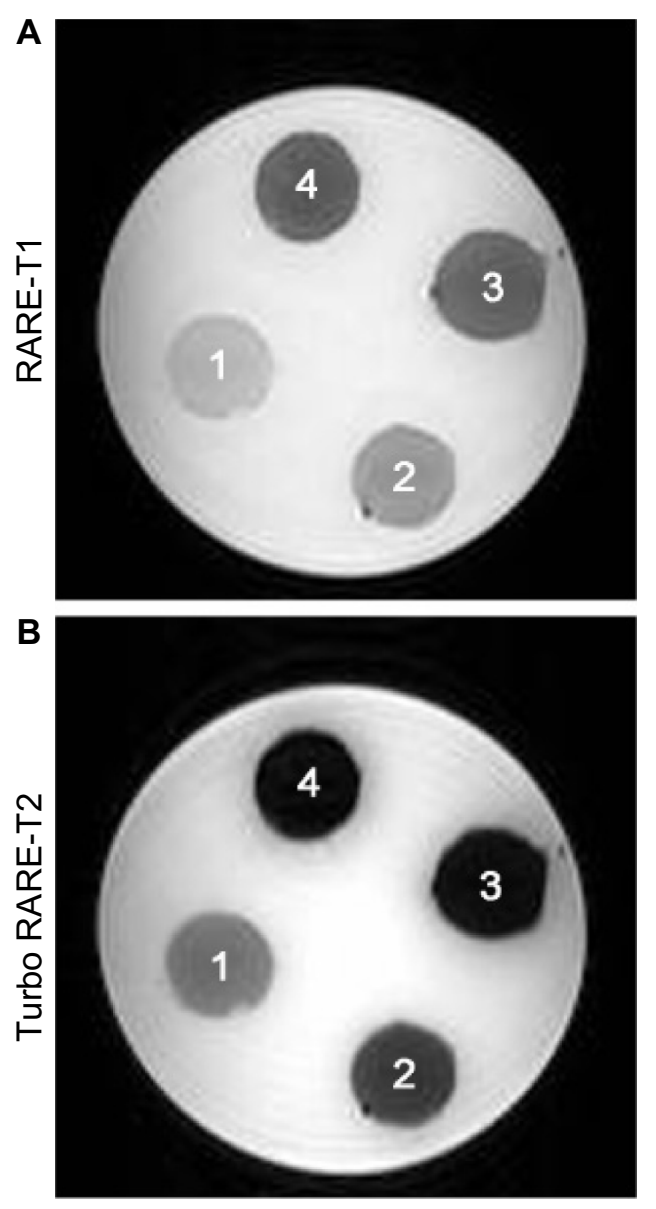

Figure 4 Magnetic resonance images of cross sections of agar phantom containing regions with different $\mathrm{Fe}^{+}$concentrations of SPION-EGF conjugates.

Notes: Presented are the TI and T2 magnetic resonance images (RARE-TI and Turbo RARE-T2 regimens, respectively) of the SPION-EGF nanoparticles in $5 \%$ agarose gel. I: $0.1 \mathrm{mM} / \mathrm{L} ; 2: 0.2 \mathrm{mM} / \mathrm{L} ; 3: 0.3 \mathrm{mM} / \mathrm{L} ; 4: 0.4 \mathrm{mM} / \mathrm{L}$.

Abbreviations: RARE, rapid acquisition with relaxation enhancement; SPION-EGF, superparamagnetic iron oxide nanoparticles conjugated with epidermal growth factor.

influence of the SPION or SPION-EGF conjugates on the C6 cell proliferation, which did not differ from control. Furthermore, we assessed the incorporation of nanoparticles into C6 cells. Following 6 hours of incubation with nanoparticles, we could observe the internalization of particles in the cytoplasm of C6 cells (Figure 5). SPION mostly accumulated in the cytoplasm in the endosome-like structures surrounding the nucleus. When SPION-EGF conjugates were applied, the amount of the incorporated particles was significantly higher in comparison to unmodified SPION (Figure 6A). The highest level of accumulation of the magnetic nanoparticles conjugated with EGF was observed after 24 hours of incubation. All the procedures were performed under standard conditions (ie, $37^{\circ} \mathrm{C}, 6 \% \mathrm{CO}_{2}$ ). When the incubation of cells was performed at $4^{\circ} \mathrm{C}$, we did not observe the internalization of nanoparticles, indicating the necessity for active transport of the nanoparticles (data not shown). The 


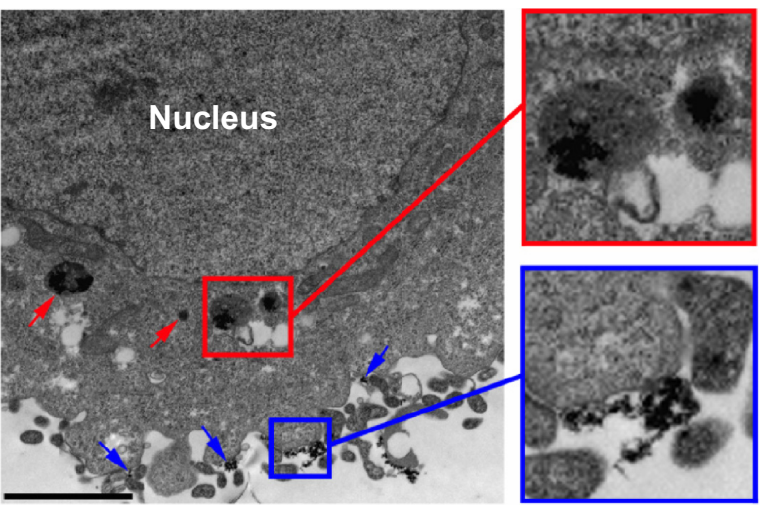

Figure 5 Transmission electron microscopy of the C6 cells incubated with SPIONs. Notes: Following incubation with SPIONs $(150 \mu \mathrm{g} / \mathrm{mL})$ for 24 hours, nanoparticles could be detected as being attached to the cell membrane (blue arrows) and incorporated into the endosome-like structures in the cytoplasm (red arrows). Scale bar: $2 \mu \mathrm{m}$.

Abbreviation: SPIONs, superparamagnetic iron oxide nanoparticles. staining of the cells for EGFR demonstrated the expression of the receptor in $\mathrm{C} 6$ cells (Figure 6B). When the cells were analyzed by TEM, we could observe the presence of SPION-EGF conjugates included as electron-dense particles in membrane structures within the cytoplasm (Figure 6C). We used immunogold labeling to characterize the subcellular localization of EEA-1. EEA-1 immunoreactivity was sparsely scattered throughout the cytoplasm and mostly accumulated in membrane structures. Immunocytochemistry demonstrated that SPION-EGF complexes were colocalized with EEA-1 (Figure 6D). We propose a mechanism of receptor-mediated endocytosis of SPION-EGF conjugates by C6 cells. Staining of the cells with an antibody against EGFR confirmed the colocalization of nanoparticles with EGF receptors in endosomes (Figure 6E). Application of a blocking anti-EGFR
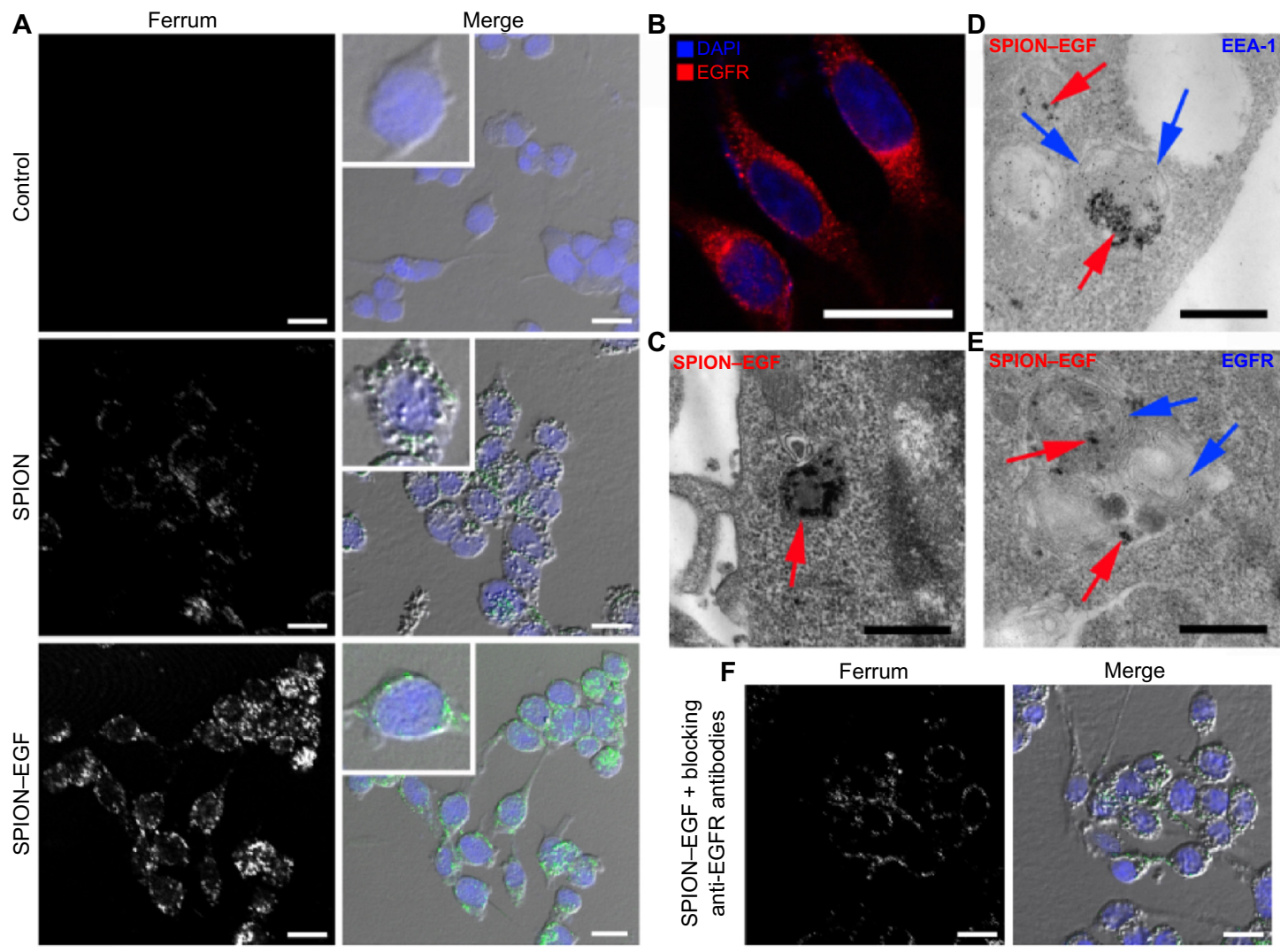

Figure 6 Assessment of the interaction of magnetic nanoparticles with C6 glioma cells by microscopy.

Notes: (A) Confocal microscopy images of the C6 cells after 24 hours of incubation with phosphate buffered saline, SPION (I50 $\mu \mathrm{g} / \mathrm{mL})$, and SPION-EGF conjugates ( $150 \mu \mathrm{g} / \mathrm{mL}$ ). Nuclei were stained with DAPI (blue). Magnetic nanoparticles were detected by reflected laser scanning at $488 \mathrm{~nm}$ (green). Scale bar: $25 \mu \mathrm{m}$. (B) Immunofluorescence image of the C6 cells stained by anti-EGFR antibodies (red). Nuclei were stained with DAPI (blue). Scale bar: $7.5 \mu \mathrm{m}$. (C) TEM of C6 cells incubated for 24 hours with SPION-EGF conjugates. Electron-dense nanoparticles were present in the cytoplasm of cells in endosome-like structures (red solid arrow). Scale bar: $500 \mathrm{~nm}$. (D) TEM and immunogold labeling of C6 cells incubated with SPION-EGF conjugates for 24 hours. For the detection of early endosomes, a rabbit anti-EEA-I polyclonal primary antibody and a gold-conjugated (I0 nm) goat anti-rabbit lgG secondary antibody were applied. In the cytoplasm of C6 cells, the colocalization of magnetic nanoparticles (red arrows) and the early endosome marker, EEA-I (blue arrows), was observed in the membrane structures. Scale bar: $500 \mathrm{~nm}$. (E) TEM and immunogold labeling of cells incubated with SPION-EGF nanoparticles. C6 cells were stained with a rabbit polyclonal anti-EGFR antibody and then with a gold-conjugated (10 nm) goat anti-rabbit lgG secondary antibody. The inclusions of nanoparticles (red arrows) were observed in multilayer EGFR-positive endosomes. Scale bar: $500 \mathrm{~nm}$. (F) Confocal microscopy images of the C6 cells treated with blocking anti-EGFR antibodies prior to incubation with SPION-EGF conjugates. A reduction in nanoparticle inclusions in glioma cells (green) was observed. Nuclei were stained with DAPI (blue). Scale bar: $25 \mu \mathrm{m}$.

Abbreviations: SPION, superparamagnetic iron oxide nanoparticle; SPION-EGF, superparamagnetic iron oxide nanoparticles conjugated with epidermal growth factor; DAPI, 4',6-diamidino-2-phenylindole; EGFR, epidermal growth factor receptor; EEA-I, early endosome antigen I; TEM, transmission electron microscopy; IgG, immunoglobulin G. 
antibody significantly reduced the incorporation of SPIONEGF conjugates in the cytoplasm of C6 cells (Figure 6F), thus indicating a role of receptor-mediated endocytosis of nanoparticles. When cells incubated with SPION were stained for EEA-1 and EGFR, we observed the incorporation of nanoparticles in early endosomes labeled with EEA-1, but these structures were not stained with the EGFR antibody (data not shown).

Accumulation of the SPION-EGF conjugates in the C6 cells also resulted in T2-weighted MRI contrast enhancement after 24 hours of treatment (Figure 7). We observed a threefold signal drop in the cells treated with conjugates in comparison to the control unmodified SPION. Thus, the T2 values after 24 hours of C6 cell incubation with SPION dropped from $51.0 \pm 1.32 \mathrm{~ms}$ in the control to $25.1 \pm 1.2 \mathrm{~ms}$. When SPION-EGF conjugates were added to the cell culture, the T2 values were further reduced to $8.3 \pm 0.3 \mathrm{~ms}(P<0.001)$. The blocking of anti-EGFR antibodies demonstrated that the change in the $\mathrm{T} 2$ values was not different from the control cells (ie, 22.9 $\pm 1.4 \mathrm{~ms}$ ), thus demonstrating the role

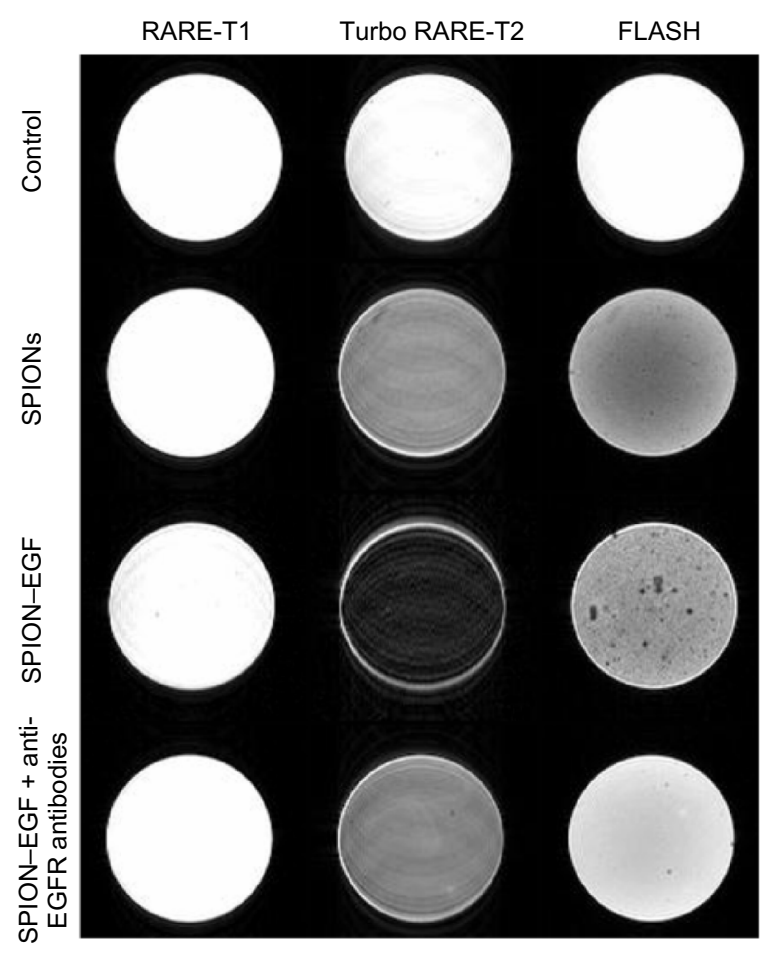

Figure $7 \mathrm{TI}$ - and T2-weighted, as well as gradient echo magnetic resonance images of $\mathrm{C} 6$ cells in agarose gel.

Notes: Left column: RARE-TI regimen; middle column: Turbo RARE-T2 regimen; right column: FLASH regimen. Rows: control cells in phosphate buffered saline; SPION (I50 $\mu \mathrm{g} / \mathrm{mL})$; SPION-EGF conjugates (150 $\mu \mathrm{g} / \mathrm{mL})$; cells blocked with antiEGFR antibodies prior to incubation with SPION-EGF conjugates $(150 \mu \mathrm{g} / \mathrm{mL})$. Abbreviations: RARE, rapid acquisition with relaxation enhancement; FLASH, fast low angle shot; SPION, superparamagnetic iron oxide nanoparticle; SPION-EGF, superparamagnetic iron oxide nanoparticle conjugated with epidermal growth factor; EGFR, epidermal growth factor receptor. of receptor-mediated endocytosis of the SPION-EGF nanoparticles. When the control isotype IgG rabbit antibody was used in the same set of experiments, we did not observe any effect on the T2 values (data not shown).

\section{In vivo imaging of $\mathrm{C} 6$ glioma by SPION-EGF conjugates}

On the 20th day following intracranial implantation of the C6 cells, animals $(n=3)$ were sacrificed, and brains were isolated for assessment of the presence of the EGFR-positive cells. Immunofluorescence analysis of the brain tumor sections demonstrated the overexpression of EGFR in C6 glioma cells throughout the tumor (Figure 8).

Following histological confirmation of EGFR overexpression in the C6 glioma, we assessed the feasibility of tumor targeting with magnetic nanoparticles. All IV injections with nanoparticles were well-tolerated by the animals. We did not observe any side effects, nor were there any behavioral abnormalities. MR images of the glioma were acquired before the administration of magnetic nanoparticles, as well as 24 hours and 48 hours after IV infusion. The C6 glioma presented as hypo- or isotensive on the T1-weighted images and hypertensive on the T2-weighted scans (Figure 9A). The mean $\mathrm{T} 2$ value for the untreated glioma was $24.2 \pm 0.8 \mathrm{~ms}$. When unmodified SPIONs were applied (Figure 9B), we did not observe a statistically significant change in the T2 values for 24 hours or 48 hours after the administration of nanoparticles $(P>0.05)$ (data not shown). From the MR images, statistically

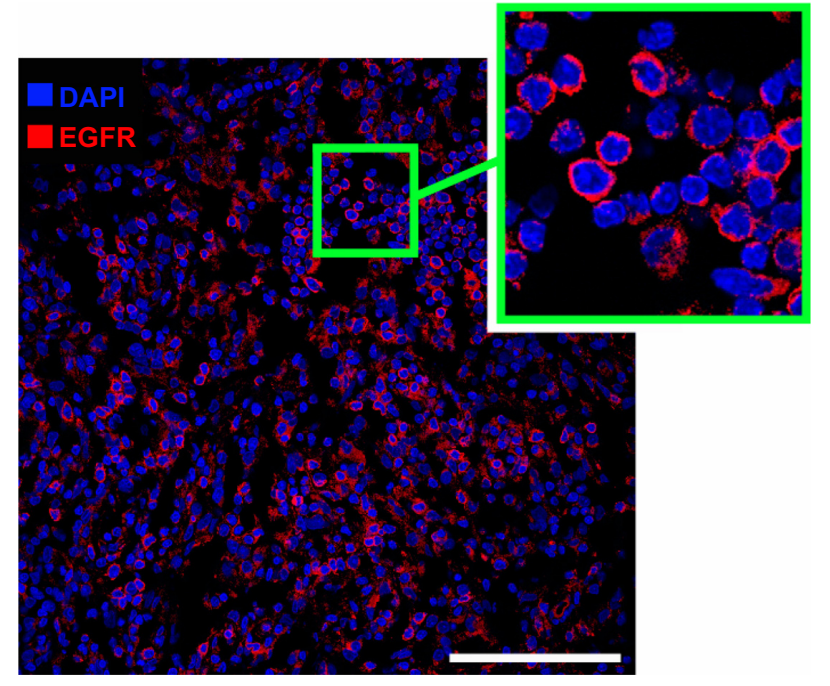

Figure 8 Immunofluorescence image of the C6 glioma.

Notes: C6 cells were stained with anti-EGFR polyclonal antibodies (red). Nuclei were stained with DAPI (blue). Scale bar: $75 \mu \mathrm{m}$.

Abbreviations: DAPI, 4',6-diamidino-2-phenylindole; EGFR, epidermal growth factor receptor. 

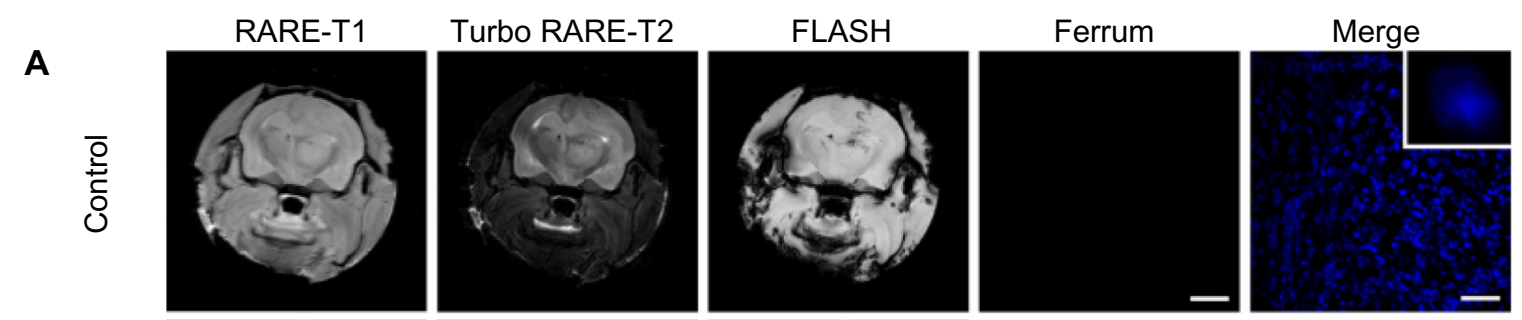

B
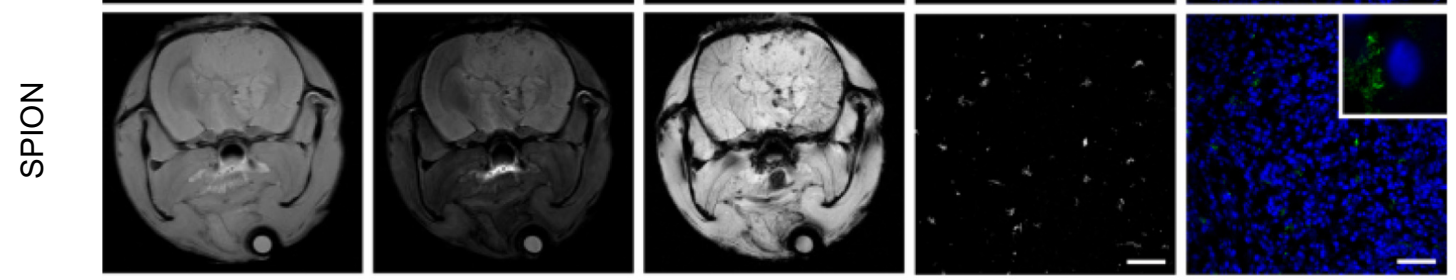

C
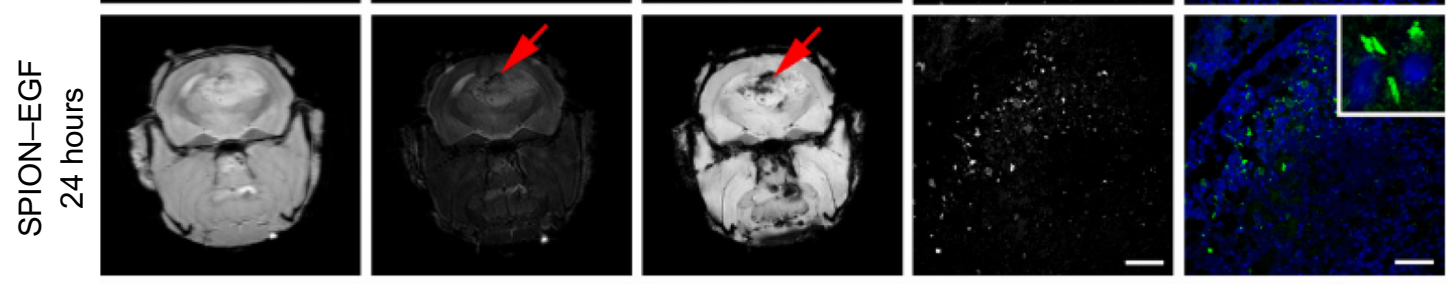

D
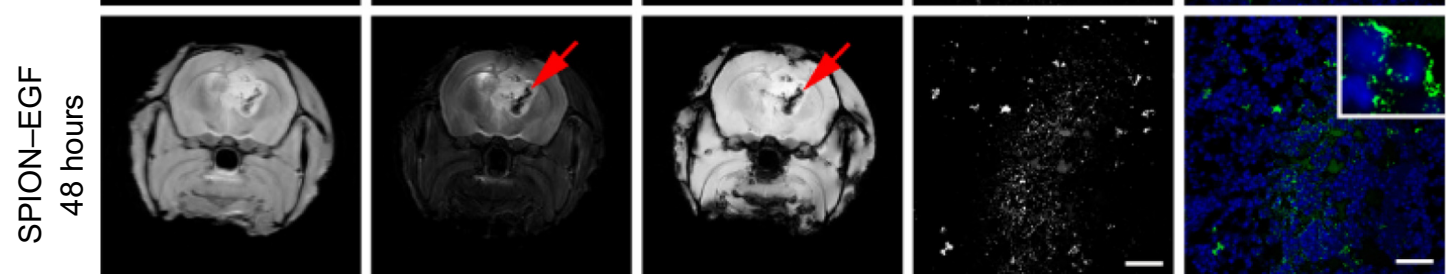

Figure $9 \mathrm{MR}$ imaging and histology of $\mathrm{C} 6$ gliomas in rats.

Notes: Coronal MR images in the RARE-TI, Turbo RARE-T2, and FLASH regimes (first three columns). MR scans of (A) control animals (treated with phosphate buffered saline); (B) animals 24 hours after intravenous treatment with SPION (0.3 mg/kg); (C) and animals treated intravenously with SPION-EGF conjugates (0.3 mg/kg) after (C) 24 or (D) 48 hours. Conjugates accumulated in the C6 glioma and presented as hypotense zones on the T2-weighted and gradient echo images (red arrows). Confocal microscopy of the tumor sections is presented in the fourth and fifth columns. Nanoparticles were detected by reflected laser scanning (green); nuclei were stained with DAPI (blue). Scale bar: $75 \mu \mathrm{m}$.

Abbreviations: RARE, rapid acquisition with relaxation enhancement; FLASH, fast low angle shot; SPION, superparamagnetic iron oxide nanoparticle; SPION-EGF, superparamagnetic iron oxide nanoparticles conjugated with epidermal growth factor receptor; MR, magnetic resonance; DAPI, 4',6-diamidino-2-phenylindole.

significant signal changes in the tumor region were observed 24 hours after IV infusion with the SPION-EGF conjugates (Figure 9C). When SPION-EGF conjugates were applied, we observed a significant decrease in the T2 signal in the zone of the tumor after 24 hours of injection to $18.4 \pm 0.8 \mathrm{~ms}$ in comparison to that of unmodified SPIONs or control untreated animals $(P<0.001)$. Thus, nanoparticles accumulated throughout the glioma and subsequently presented as hypotense zones on the T2-weighted images. Corresponding T2 maps of the treated tumors calculated from the MSME images demonstrated a decrease in $\mathrm{T} 2$ values. In the zone of the hypotensive signal, there was a further reduction in T2 values to $14.7 \pm 0.5 \mathrm{~ms}$. Forty-eight hours following the IV injection of SPION-EGF conjugates (Figure 9D), and due to the accumulation of conjugates in the glioma, we could observe a decrease in the $\mathrm{T} 2$ values in the tumor, especially in the hypotensive zone, to $16.8 \pm 0.4 \mathrm{~ms}$ (tumor) and $12.3 \pm 0.4 \mathrm{~ms}$ (hypotensive) respectively. Confocal microscopy of the tumor sections with reflected laser scanning demonstrated greater accumulation of SPION-EGF conjugates at the tumor site in comparison to unconjugated SPIONs. When tumor sections of the animals treated with unmodified SPION were assessed, most had accumulated in zones of necrosis in the glioma. In certain visual fields, we observed the incorporation of SPIONs inside solitary cells. IV infusion of the SPION-EGF conjugates resulted in the significant retention of magnetic nanoparticles in the C6 glioma. Throughout the tumor, we observed zones of the cells with increased accumulation of the conjugates. At higher magnification, nanoparticles presented in the cytoplasm of C6 cells, surrounding the nucleus (Figure 9). The pattern of intracellular localization of SPION-EGF conjugates in the tumor as green dots resembled the pattern of nanoparticles incorporation in C6 cells in in vitro studies, thus indicating the receptor-mediated mechanism of conjugate uptake in animals. The analysis of normal brain tissues did not reveal any nonspecific retention of SPION or SPION-EGF conjugates in cells 
or in the tumor microenvironment. We observed the presence of the magnetic nanoparticles in the brain vessels (ie, endothelial cells), as well as inside the lumen of the pial arteries. Inside the endothelial cells on confocal microscopy, SPION or SPIONEGF nanoparticles localized in the cytoplasm, surrounding the nucleus (data not shown). Nanoparticles appeared to be present within cytoplasm, forming coarse solitary aggregates. There was no difference in the quantity of aggregates inside the endothelial cells of the animals treated with SPION or EGF conjugates.

For MR differentiation of the necrotic zone in the tumor from the specific accumulation of nanoparticles, T2 values were also measured and a histological assay was subsequently performed. Thus, in control animals, the hypotensive zone was characterized by a T2 value of $25.7 \pm 1.1 \mathrm{~ms}$ (Figure 9A), which was significantly different from the $\mathrm{T} 2$ value of animals treated with SPION-EGF conjugates (ie, $12.3 \pm 0.4 \mathrm{~ms})(P<0.001)$. Moreover, confocal microscopy analysis clearly demonstrated the specific accumulation of SPION-EGF conjugates in tumor cells, which led to the significant drop in the T2 signal.

\section{Discussion}

SPIONs functionalized with EGF, which were investigated in a series of in vitro experiments, did not demonstrate toxicity or influence on $\mathrm{C} 6$ cell proliferation at a diagnostic concentration (150 $\mu \mathrm{g} / \mathrm{mL}$ ) according to Trypan blue or MTT assay. These results correspond to our earlier data and to data from other studies. ${ }^{1,2,21}$ Subsequent in vivo analysis of the SPION-EGF conjugates showed the feasibility and safety of IV administration of these nanoparticles. We did not observe any side effects (ie, behavioral changes) after the infusion of particles in animals. Though we did not assess the chronic toxicity of the magnetic nanoparticles due to their accumulation in the organs (for example, liver, spleen, kidney, bone marrow, and so on) these experiments will be performed in the future.

The designed SPION-EGF conjugates demonstrated high efficiency as an MR contrast agent. The level of tumor contrast enhancement of IV delivered nanoparticles was not inferior to the previously reported effect of EGFRvIII-IONPs that were locally infused into the tumor. ${ }^{2}$ In our study, we observed the accumulation of nanoparticles in the glioma in the zones of hypotensive signal on T2-weighted images (Figure 9). Thus, hypotensive zones were heterogeneously detected on the MR scans throughout the glioma. One could speculate that such an MR pattern of nanoparticle accumulation is determined by the heterogeneous expression of wtEGFR in the tumor.

According to the results of immunofluorescence analysis of the C6 glioma sections, the EGFR was heterogeneously overexpressed throughout the tumor, thus explaining the MR pattern of nanoparticle uptake (Figure 8). The MR pattern of nanoparticle retention in the C6 glioma corresponded to that previously described in models of EGFR-overexpressing tumors (ie, melanomas and hepatomas). ${ }^{21}$ Intriguingly, we observed a signal loss throughout the entire brain's vascular tree on the T2-weighted MR images, especially on the gradient echo images (FLASH regimen) (Figure 9). Previously, Sirol et $\mathrm{al}^{25}$ reported that due to the slow flow within the vessel lumen, the incomplete suppression of the blood signal could mimic the uptake of the probe within the endothelium. According to the immunofluorescence evaluation of the brain sections, we observed the incorporation of the SPION or SPION-EGF nanoparticles inside the cytoplasm of the endothelial cells (Figure 9). The retention of the magnetic nanoparticles inside the endothelium could lead to the decrease of the T2 values.

Systemic delivery of nanoparticles to brain tumors has been actively discussed due to the blood-brain barrier and non-specific uptake of particles by the reticuloendothelial system. However, it has been shown that the tumor's vascular structure is significantly different in gliomas and is characterized by increased permeability. ${ }^{26}$ Conjugation of SPIONs with EGF increased the retention of particles in the tumor; thus, we observed a dramatic accumulation of SPION-EGF conjugates throughout the glioma (Figure 9). The MR detectable accumulation of these conjugates started to appear 24 hours after IV injection, and it further increased after 48 hours. Thus, the T2 values in the zone of the hypotensive signal in the glioma had decreased by twofold in animals 48 hours after SPION-EGF injection, in comparison to control rats and animals injected with unmodified SPION. Subsequent histological analysis of the brain confirmed the localization of nanoparticles in the tumor site, but not in normal tissues. SPION-EGF conjugates were mostly localized in the cytoplasm of tumor cells. This corresponds to the results from the in vitro studies, where we demonstrated receptor-mediated endocytosis in C6 cell culture (Figure 6). Furthermore, the incubation of cells with a blocking anti-EGFR antibody prior to the addition of SPION-EGF conjugates resulted in decreased cellular uptake of the particles, thus demonstrating the role of EGFR in nanoparticle incorporation (Figure 6). The role of EGFR was further shown with the use of the blocking antibody in the MR studies by a decrease in the incorporation of conjugates indicated by the T2-weighted images (Figure 7).

For the prevention of particle uptake by the reticuloendothelial system in the liver (Kupffer cells), spleen, and circulating macrophages, other routes of nanoparticle 
administration could be applied. Recently, Chertok et $\mathrm{al}^{27}$ reported the possibility of intracarotid administration of polyethyleneimine (PEI)-modified magnetic nanoparticles (GPEI) in the 9L-gliosarcoma model. The authors clearly demonstrated a 30-fold increase in tumor entrapment of GPEI compared to that seen with IV administration. ${ }^{28} \mathrm{~A}$ further increase in the intratumoral accumulation of SPIONs could be achieved by magnetic targeting. Since the iron oxide core of the SPION has high magnetic responsiveness, an external magnetic field could significantly increase the retention of nanoparticles at the tumor site. ${ }^{28-31}$

Modification of the magnetic nanoparticles could increase their therapeutic potency. In particular, application of the toxic peptide chlorotoxin, which specifically binds to matrix metalloproteinase-2, has been shown to significantly inhibit tumor invasion. ${ }^{32-34}$ Also, conjugation of SPIONs with chemotherapeutic agents could enhance the activity of the nanoparticles. Recently, several studies have demonstrated the theranostic potency of particles coupled with various agents, including methotrexate, ${ }^{35,36}$ mitoxantrone, ${ }^{37}$ epirubicin, ${ }^{38}$ gemcitabine, ${ }^{39}$ doxorubicin, ${ }^{40}$ and many others. It is likely that the conjugation of SPION-EGF particles with chemotherapeutic drugs could increase targeted drug delivery and reduce the side effects of these drugs.

These results reveal that magnetic nanoparticles conjugated with EGF exhibit high MR contrast potential and can be applied as a diagnostic agent. Furthermore, the extent of tumor retention of SPION-EGF conjugates in comparison to unmodified nanoparticles reveals the tumor selectivity of the designed agent. These data warrant further investigation of SPION-EGF nanoparticles concerning their pharmacokinetic properties and optimization for clinical application.

\section{Acknowledgments}

The study was supported by the Federal Medical-Biology Agency (FMBA RF) grant No 40.002.12.0 of February 20, 2012, and by the Russian Federation Ministry of Education and Science within the framework of the Federal Grant Program "Scientific and Educational Human Resources of Innovative Russia" under State Contract No 14.B37.21.0568.

The authors thank Pavel P Klein for preparation of the illustrations, as well as Olga G Genbach, Tatyana V Zakoldaeva, Irina V Kononova, Yulia I Shevchuk, Dmitriy N Suslov, and Oleg V Galibin for assistance with the animal experiments.

\section{Disclosure}

The authors report no conflicts of interest in this work.

\section{References}

1. Wankhede M, Bouras A, Kaluzova M, Hadjipanayis CG. Magnetic nanoparticles: an emerging technology for malignant brain tumor imaging and therapy. Expert Rev Clin Pharmacol. 2012;5(2): 173-186.

2. Hadjipanayis CG, Machaidze R, Kaluzova M, et al. EGFRvIII antibody-conjugated iron oxide nanoparticles for magnetic resonance imaging-guided convection-enhanced delivery and targeted therapy of glioblastoma. Cancer Res. 2010;70(15):6303-6312.

3. Maier-Hauff K, Ulrich F, Nestler D, et al. Efficacy and safety of intratumoral thermotherapy using magnetic iron-oxide nanoparticles combined with external beam radiotherapy on patients with recurrent glioblastoma multiforme. J Neurooncol. 2011;103(2):317-324.

4. Tong S, Hou S, Zheng Z, Zhou J, Bao G. Coating optimization of superparamagnetic iron oxide nanoparticles for high T2 relaxivity. Nano Lett. 2010;10(11):4607-4613.

5. Furnari FB, Fenton T, Bachoo RM, et al. Malignant astrocytic glioma: genetics, biology, and paths to treatment. Genes Dev. 2007;21(21): 2683-2710.

6. Watanabe K, Tachibana O, Sata K, Yonekawa Y, Kleihues P, Ohgaki H. Overexpression of the EGF receptor and p53 mutations are mutually exclusive in the evolution of primary and secondary glioblastomas. Brain Pathol. 1996;6(3):217-223; discussion 23-24.

7. Bublil EM, Yarden Y. The EGF receptor family: spearheading a merger of signaling and therapeutics. Curr Opin Cell Biol. 2007;19(2): 124-134.

8. Gan HK, Kaye AH, Luwor RB. The EGFRvIII variant in glioblastoma multiforme. J Clin Neurosci. 2009;16(6):748-754.

9. Nagane M, Lin H, Cavenee WK, Huang HJ. Aberrant receptor signaling in human malignant gliomas: mechanisms and therapeutic implications. Cancer Lett. 2001;162 Supp1:S17-S21.

10. Mishima K, Johns TG, Luwor RB, et al. Growth suppression of intracranial xenografted glioblastomas overexpressing mutant epidermal growth factor receptors by systemic administration of monoclonal antibody (mAb) 806, a novel monoclonal antibody directed to the receptor. Cancer Res. 2001;61(14):5349-5354.

11. Rivera F, Vega-Villegas ME, López-Brea MF. Cetuximab, its clinical use and future perspectives. Anticancer Drugs. 2008;19(2):99-113.

12. Eller JL, Longo SL, Kyle MM, Bassano D, Hicklin DJ, Canute GW. Anti-epidermal growth factor receptor monoclonal antibody cetuximab augments radiation effects in glioblastoma multiforme in vitro and in vivo. Neurosurgery. 2005;56(1):155-162; discussion 162.

13. Sampson JH, Archer GE, Mitchell DA, et al. An epidermal growth factor receptor variant III-targeted vaccine is safe and immunogenic in patients with glioblastoma multiforme. Mol Cancer Ther. 2009;8(10):2773-2779.

14. Kohno M, Horibe T, Haramoto M, et al. A novel hybrid peptide targeting EGFR-expressing cancers. Eur J Cancer. 2011;47(5):773-783.

15. Kang CS, Zhang ZY, Jia ZF, et al. Suppression of EGFR expression by antisense or small interference RNA inhibits U251 glioma cell growth in vitro and in vivo. Cancer Gene Ther. 2006;13(5):530-538.

16. Quatrale AE, Porcelli L, Silvestris N, Colucci G, Angelo A, Azzariti A. EGFR tyrosine kinases inhibitors in cancer treatment: in vitro and in vivo evidence. Front Biosci (Landmark Ed). 2011;16: 1962-1972.

17. Kullberg EB, Nestor M, Gedda L. Tumor-cell targeted epiderimal growth factor liposomes loaded with boronated acridine: uptake and processing. Pharm Res. 2003;20(2):229-236.

18. Mamot C, Drummond DC, Greiser U, et al. Epidermal growth factor receptor (EGFR)-targeted immunoliposomes mediate specific and efficient drug delivery to EGFR- and EGFRvIII-overexpressing tumor cells. Cancer Res. 2003;63(12):3154-3161.

19. Kim IY, Kang YS, Lee DS, et al. Antitumor activity of EGFR targeted pH-sensitive immunoliposomes encapsulating gemcitabine in A549 xenograft nude mice. J Control Release. 2009;140(1):55-60.

20. Sandoval MA, Sloat BR, Lansakara-P DS, et al. EGFR-targeted stearoyl gemcitabine nanoparticles show enhanced anti-tumor activity. J Control Release. 2012;157(2):287-296. 
21. Nikolaev BP, Marchenko YY, Yakovleva LY, et al. Magnetic epidermal growth factor conjugate for targeted delivery to grafted tumor in mouse model. IEEE Transactions on Magnetics. 2013;49(1):429-435.

22. Massart R. Preparation of aqueous magnetic liquids in alkaline and acidic media. IEEE Transactions on Magnetics. 1981;17(2):1247-1248.

23. Tassa C, Shaw SY, Weissleder R. Dextran-coated iron oxide nanoparticles: a versatile platform for targeted molecular imaging, molecular diagnostics, and therapy. Acc Chem Res. 2011;44(10):842-852.

24. Marchenko YY, Shishkin AN, Yakovleva LY, Nikolaev BP. The magnetic relaxation platform for biosensing cancer markers: the relaxivity of magnetic nanoparticles conjugated with epidermal growth factor under influence of its antibody. In: Program and abstracts of the Nuclear Magnetic Resonance in Condensed Matter 9th Meeting: NMR in Heterogeneous Systems; July 9-13, 2012; St Petersburg, Russia 104.

25. Sirol M, Itskovich VV, Mani V, et al. Lipid-rich atherosclerotic plaques detected by gadofluorine-enhanced in vivo magnetic resonance imaging. Circulation. 2004;109(23):2890-2896.

26. Chertok B, David AE, Huang Y, Yang VC. Glioma selectivity of magnetically targeted nanoparticles: a role of abnormal tumor hydrodynamics. J Control Release. 2007;122(3):315-323.

27. Chertok B, David AE, Yang VC. Polyethyleneimine-modified iron oxide nanoparticles for brain tumor drug delivery using magnetic targeting and intra-carotid administration. Biomaterials. 2010;31(24): 6317-6324.

28. Chertok B, Moffat BA, David AE, et al. Iron oxide nanoparticles as a drug delivery vehicle for MRI monitored magnetic targeting of brain tumors. Biomaterials. 2008;29(4):487-496.

29. Alexiou C, Arnold W, Klein RJ, et al. Locoregional cancer treatment with magnetic drug targeting. Cancer Res. 2000;60(23):6641-6648.

30. Lübbe AS, Bergemann C, Huhnt W, et al. Preclinical experiences with magnetic drug targeting: tolerance and efficacy. Cancer Res. 1996; 56(20):4694-4701.
31. Lübbe AS, Bergemann C, Riess H, et al. Clinical experiences with magnetic drug targeting: a phase I study with $4^{\prime}$-epidoxorubicin in 14 patients with advanced solid tumors. Cancer Res. 1996;56(20):4686-4693.

32. Lyons SA, O'Neal J, Sontheimer H. Chlorotoxin, a scorpion-derived peptide, specifically binds to gliomas and tumors of neuroectodermal origin. Glia. 2002;39(2):162-173.

33. Deshane J, Garner CC, Sontheimer H. Chlorotoxin inhibits glioma cell invasion via matrix metalloproteinase-2. J Biol Chem. 2003;278(6): 4135-4144.

34. Veiseh O, Gunn JW, Kievit FM, et al. Inhibition of tumor-cell invasion with chlorotoxin-bound superparamagnetic nanoparticles. Small. 2009;5(2):256-264.

35. Kohler N, Sun C, Fichtenholtz A, Gunn J, Fang C, Zhang M. Methotrexate-immobilized poly(ethylene glycol) magnetic nanoparticles for MR imaging and drug delivery. Small. 2006;2(6):785-792.

36. Kohler N, Sun C, Wang J, Zhang M. Methotrexate-modified superparamagnetic nanoparticles and their intracellular uptake into human cancer cells. Langmuir. 2005;21(19):8858-8864.

37. Lee KJ, An JH, Chun JR, et al. In vitro analysis of the anti-cancer activity of mitoxantrone loaded on magnetic nanoparticles. J Biomed Nanotechnol. 2013;9(6):1071-1075.

38. Jalalian SH, Taghdisi SM, Shahidi Hamedani N, et al. Epirubicin loaded super paramagnetic iron oxide nanoparticle-aptamer bioconjugate for combined colon cancer therapy and imaging in vivo. Eur J Pharm Sci. 2013;50(2):191-197.

39. Viota JL, Carazo A, Munoz-Gamez JA, et al. Functionalized magnetic nanoparticles as vehicles for the delivery of the antitumor drug gemcitabine to tumor cells. Physicochemical in vitro evaluation. Mater Sci Eng C Mater Biol Appl. 2013;33(3):1183-1192.

40. Erten A, Wrasidlo W, Scadeng M, et al. Magnetic resonance and fluorescence imaging of doxorubicin-loaded nanoparticles using a novel in vivo model. Nanomedicine. 2010;6(6):797-807. 


\section{Supplementary material}

A

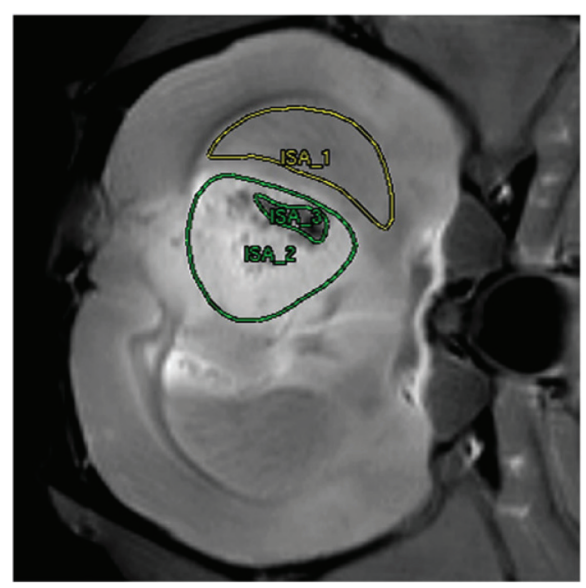

B

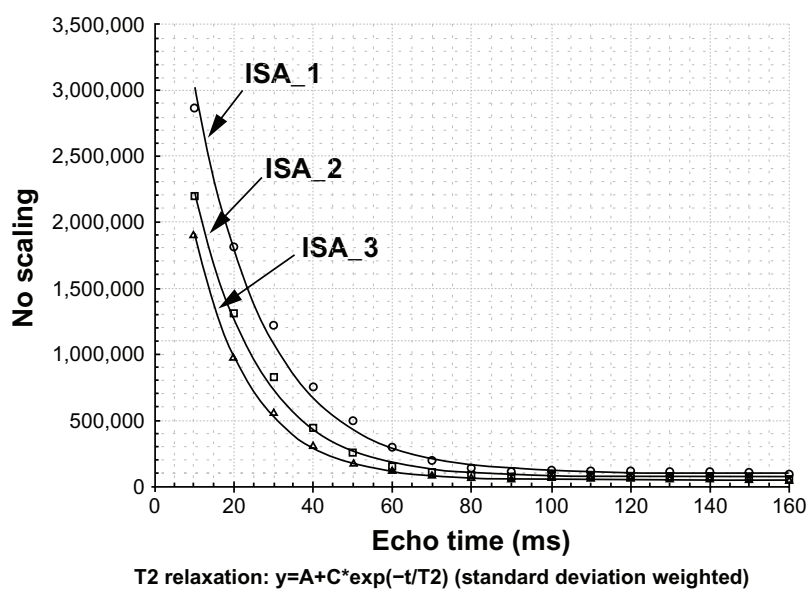

Figure SI Magnetic resonance image of the C6 glioma 48 hours after intravenous injection of the SPION-EGF conjugate.

Notes: (A) On the obtained MSME images, the regions of interest for calculating T2 values was defined over the tumor area (ie, ISA_2), over the area of hypotense signal (ie, ISA 3), and over the normal brain tissue (ie, ISA I). (B) The corresponding histogram of the T2 relaxation values for the generated regions of interest is presented. Abbreviations: SPION-EGF, superparamagnetic iron oxide nanoparticles conjugated with epidermal growth factor receptor; MSME, multiscan-multiecho.

\section{Publish your work in this journal}

The International Journal of Nanomedicine is an international, peerreviewed journal focusing on the application of nanotechnology in diagnostics, therapeutics, and drug delivery systems throughou the biomedical field. This journal is indexed on PubMed Central,

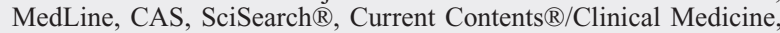

Journal Citation Reports/Science Edition, EMBase, Scopus and the Elsevier Bibliographic databases. The manuscript management system is completely online and includes a very quick and fair peer-review system, which is all easy to use. Visit http://www.dovepress.com/ testimonials.php to read real quotes from published authors.

\footnotetext{
Submit your manuscript here: http://www.dovepress.com/international-journal-of-nanomedicine-journal
} 